\title{
Sub-microscopic malaria cases and mixed malaria infection in a remote area of high malaria endemicity in Rattanakiri province, Cambodia: implication for malaria elimination
}

Nicolas Steenkeste ${ }^{1 *}$, William O Rogers ${ }^{2}$, Lucy Okell ${ }^{3}$, Isabelle Jeanne ${ }^{4}$, Sandra Incardona', Linda Duval ${ }^{5}$, Sophy Chy ${ }^{1}$, Sean Hewitt ${ }^{6}$, Monidarin Chou $^{7}$, Duong Socheat ${ }^{8}$, François-Xavier Babin ${ }^{9}$, Frédéric Ariey ${ }^{1}$, Christophe Rogier ${ }^{10}$

\begin{abstract}
Background: Malaria microscopy and rapid diagnostic tests are insensitive for very low-density parasitaemia. This insensitivity may lead to missed asymptomatic sub-microscopic parasitaemia, a potential reservoir for infection. Similarly, mixed infections and interactions between Plasmodium species may be missed. The objectives were first to develop a rapid and sensitive PCR-based diagnostic method to detect low parasitaemia and mixed infections, and then to investigate the epidemiological importance of sub-microscopic and mixed infections in Rattanakiri Province, Cambodia.

Methods: A new malaria diagnostic method, using restriction fragment length polymorphism analysis of the cytochrome $b$ genes of the four human Plasmodium species and denaturing high performance liquid chromatography, has been developed. The results of this RFLP-dHPLC method have been compared to 1) traditional nested PCR amplification of the 185 rRNA gene, 2) sequencing of the amplified fragments of the cytochrome b gene and 3) microscopy.

Blood spots on filter paper and Giemsa-stained blood thick smears collected in 2001 from 1,356 inhabitants of eight villages of Rattanakiri Province have been analysed by the RFLP-dHPLC method and microscopy to assess the prevalence of sub-microscopic and mixed infections.

Results: The sensitivity and specificity of the new RFLP-dHPLC was similar to that of the other molecular methods. The RFLP-dHPLC method was more sensitive and specific than microscopy, particularly for detecting low-level parasitaemia and mixed infections. In Rattanakiri Province, the prevalences of Plasmodium falciparum and Plasmodium vivax were approximately two-fold and three-fold higher, respectively, by RFLP-dHPLC (59\% and 15\%, respectively) than by microscopy (28\% and $5 \%$, respectively). In addition, Plasmodium ovale and Plasmodium malariae were never detected by microscopy, while they were detected by RFLP-dHPLC, in $11.2 \%$ and $1.3 \%$ of the blood samples, respectively. Moreover, the proportion of mixed infections detected by RFLP-dHPLC was higher (23\%) than with microscopy (8\%).
\end{abstract}

Conclusions: The rapid and sensitive molecular diagnosis method developed here could be considered for mass screening and ACT treatment of inhabitants of low-endemicity areas of Southeast Asia.

\footnotetext{
* Correspondence: nicolas.steenkeste@gmail.com

'Unité d'Epidémiologie Moléculaire, Institut Pasteur du Cambodge, Phnom
}

Penh, Cambodia 


\section{Background}

The development of sensitive PCR-based methods for malaria diagnosis has highlighted the low sensitivity of malaria microscopy for very low-level parasitaemia $(<50$ parasites/ $\mu \mathrm{l}$ ). The low sensitivity of microscopy may have at least two important consequences for malaria control and eradication efforts. First, asymptomatic sub-microscopic parasitaemia may serve as a reservoir for infection even when very efficient rapid diagnosis and treatment programmes have been implemented. Second, mixed infections may be overlooked when one species is present at low parasitaemia, and clinically or epidemiologically important interactions between species may be missed.

Current malaria control methods in Southeast Asia rely largely on early detection and treatment; control based on insecticide-treated bed nets (ITN) may be less effective in areas where malaria is primarily acquired not at home but by working age men engaged in mining, hunting, or logging in the forest. Since individuals with asymptomatic parasitaemia will not be identified by early detection and treatment programmes, they may continue to serve as a source of infection for vector mosquitoes, complicating control measures. It is clear that PCR-based methods can detect sub-microscopic parasitaemia [1-4]; it remains to be determined how common such cases of parasitaemia are in the field under different ecological conditions and what effect they may have on transmission.

Accurate detection of mixed infections is important for both clinical and epidemiological reasons. The four Plasmodium species, which commonly infect humans, have somewhat different clinical characteristics. Plasmodium falciparum is the most lethal species, causing severe malarial anaemia and cerebral malaria and, consequently, the vast majority of malaria deaths. Plasmodium vivax and Plasmodium ovale may persist within the liver as hypnozoites causing relapses even after treatment with blood schizonticides. Plasmodium malariae may cause chronic asymptomatic parasitaemia and may lead to renal failure via unclear mechanisms [5]. Finally, Plasmodium knowlesi is a newly emergent malaria parasite in Southeast Asia [6,7]. How these clinical characteristics are modified in mixed species infections is not clear. Voza et al in 2005 found a speciesspecific inhibition of cerebral malaria in mice coinfected with Plasmodium spp [8]. In human, according to several studies in Ivory Coast [9], Sri Lanka [10] and Thailand [11], the severity of infection may be modulated by mixed infections. In a study carried out in Vanuatu, $P$. falciparum appeared to be associated with a reduced P. vivax parasitaemia $[12,13]$, but the reverse effect has been observed in another study [14]. There seems to be a strong interaction between these two malaria species, and $P$. vivax co-infection has even been reported to decrease treatment failures of $P$. falciparum [15]. In other studies, $P$. falciparum - P. vivax mixed infections affected the clinical outcome in patients $[13,16]$. Examples of $P$. malariae and $P$. ovale co-infections with $P$. falciparum protecting against malaria symptoms have also been reported [17]. Studies with a Plasmodium berghei and Plasmodium yoelii co-infection model in mice appear to confirm that there can be a strong cross-protective effect of mixed species infections [18]. Mixed infections may have important epidemiological effects. For example, if $P$. vivax parasitaemia is suppressed by co-infection with $P$. falciparum, then effective control of $P$. falciparum malaria in an area might be followed by an increase in $P$. vivax transmission.

Studies of mixed species infections based only on microscopy may underestimate their importance. The frequencies of minority species, such as $P$. malariae and $P$. ovale, are largely underestimated by microscopy [19-21]. PCR-based methods are more sensitive [1-4] and more readily detect mixed infections. Using PCR diagnosis, between one third and half of malaria infections in a study in Thailand were found to be mixed species infections [22].

In order to investigate the epidemiological importance of sub-microscopic and mixed species infections, a highly sensitive PCR-based diagnostic method was developed using amplification of a fragment of the cytochrome $b$ gene, followed by Restriction Fragment Length Polymorphism (RFLP) analysis using Denaturing High Performance Liquid Chromatography (dHPLC) to detect amplification and restriction products. Results of the RFLP-dHPLC method were first compared to traditional PCR and microscopy. This highly sensitive method was then used to analyze samples collected in 2001 in malaria prevalence surveys in eight villages in Rattanakiri Province, a site of high malaria transmission in Cambodia, and assess the prevalence and importance of sub-microscopic and mixed infections in this population.

\section{Methods}

\section{Study area and population}

Rattanakiri province is located in North-Eastern Cambodia, close to the borders with Laos and Vietnam (Figure 1). Malaria is transmitted by Anopheles dirus, Anopheles maculatus and Anopheles minimus [23,24]. In 2001, the number of slide-confirmed malaria cases confirmed in Rattanakiri province by the National Malaria Control Programme (CNM) was 1,165 for P. falciparum (71.9\%), 424 for $P$. vivax (26.1\%) and 31 for P. malariae (2\%) [25].

A cross-sectional prevalence survey was conducted in September 2001 in 36 villages classified as 'high-risk' $(<1 \mathrm{~km}$ of the forest) of Rattanakiri province [26]. 


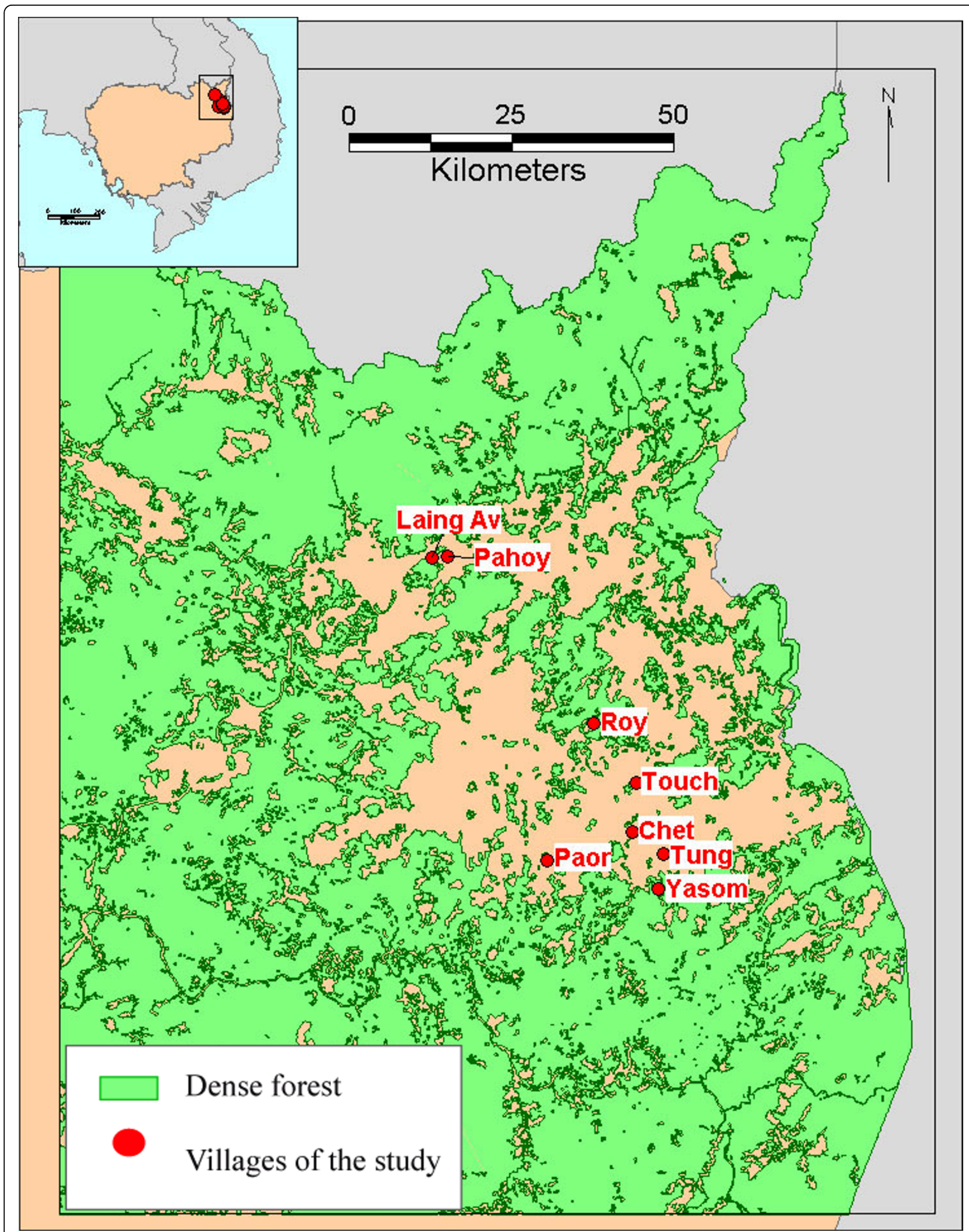

Figure 1 The study area and villages in Rattanakiri province, and their location in Cambodia. (lat/long: Yasom 13.583/107.283; Roy 13.814/ 107.193; Paor 13.624/107.125; Chet 13.662/107.246; Tung 13.631/107.290; Touch 13.731/107.253; Laing Av 14.046/106.964; Pahoy 14.047/106.987) 
Approximately $20 \mu \mathrm{L}$ of finger prick blood were collected on Whatman $3 \mathrm{M}$ filter paper. Thin and thick blood smears were prepared, and data on age, sex and temperature were collected. Blood spots were stored at $-20^{\circ} \mathrm{C}$.

For the present study, eight villages from the 2001 survey were randomly selected. Those villages belonged to three ethnic minorities; respectively, Tampuon (Yasom, 204 samples; Roy, 206 samples; Chet, 204 samples and Paor, 209 samples), Jarai (Tung, 143 samples and Touch, 143 samples) and Brao (Laing Av, 132 samples and Pahoy, 134 samples).

\section{Microscopic diagnosis}

Thin smears were fixed in methanol. Both thin and thick smears were stained with $3 \%$ Giemsa for 30 minutes at room temperature. Examination was performed by experienced microscopists at the National Centre for Parasitology, Entomology and Malaria Control in Phnom Penh. At least 100 thick film fields with 1,000x magnification were examined before a slide was considered negative. Parasite species and stages were confirmed on the thin film. Parasite densities were classified according WHO recommendations: class 1 for 1-10 parasites per 100 thick film fields; class 2 for 11-100 parasites per 100 fields; class 3 for 1-10 parasites per single field; class 4 for 11-100 parasites per single field; class 5 for $>100$ parasites per single field.

\section{DNA extraction}

Parasite DNA was extracted from a piece of $4 \mathrm{~mm}$ diameter of blood spots of Whatman $3 \mathrm{M}$ filter paper, using the Instagene resin (Biorad, Germany) as previously described [27].

\section{S rRNA species-specific nested PCR, standard PCR}

The nested PCR method based on the $18 S$ rRNA gene marker [28] adapted for epidemiological studies was performed as described [29].

\section{Restriction Fragment Length Polymorphism (RFLP) and dHPLC}

Nested PCR amplification and Alu I restriction digestion of the Plasmodium cytochrome $b$ gene was performed as previously described $[27,30]$. Five $\mu$ l of each restriction digested PCR product were injected with a 96 well autosampler for DHPLC analysis in the WAVE DNA Fragment Analysis System (Transgenomic, Santa Clara, CA) with a variable wave-length detector set at $260 \mathrm{~nm}$. To separate DNA fragments, the analysis was performed on a DNASepTM column (Transgenomic, Inc.) at $50^{\circ} \mathrm{C}$ with a flow rate of $0.9 \mathrm{ml} / \mathrm{min}$. DNA fragments were eluted with a linear gradient mixture of Buffer A: 0.1 M triethylammonium acetate (TEAA) pH 7.0 (Transgenomic) and Buffer
B: $0.1 \mathrm{M}$ TEAA/25\% acetonitrile (ACN) pH 7.0. Elution started from $46 \%$ to $59.1 \%$ of buffer B over a period 13.5 min. The column was regenerated with the buffer D: $75 \%$ ACN pH 7.0 and re-used.

\section{Cytochrome $b$ SNP identification}

Sequencing reactions were performed on both strands of the cytochrome $b$ PCR product using internal primers and ABI Prism BigDye Terminator chemistry. Sequencing reactions were run on ABI3730XL (Applied Biosystems) at Macrogen ${ }^{\odot}$ (Korea). The analysis of the sequence was performed with Seqscape software v.2.0 (Applied Biosystems). An algorithm based on 11 selected SNPs has previously been developed based on an alignment of published cytochrome b reference sequences of $P$. falciparum, $P$. vivax, $P$. malariae and $P$. ovale, allowing identification of each species [27].

\section{Reference genomic DNA}

Genomic DNA from P. falciparum was extracted from a continuous culture of the 3D7 strain. DNA from the P. vivax Belem strain was kindly provided by Peter David (Institut Pasteur, Paris, France). Plasmodium malariae and P. ovale DNA as well as human control DNA from a non-infected person were kindly provided by Georges Snounou (Muséum d'Histoire Naturelle, Paris, France). DNA from patients with pure $P$. malariae infections were kindly provided by Eric Legrand (Institut Pasteur de Cayenne, French Guiana).

\section{Statistical analysis}

All statistical analyses were performed using the STATA 10 software (Stata Corporation, College Station, TX). Prevalence rates and their $95 \%$ confidence intervals were estimated using the svy commands to take into account the sampling design (clustered by village). McNemar's exact test was used for paired analysis of the results of the diagnostic methods applied to the same blood samples. The associations of independent variables with malaria prevalence were tested using logistic regression models with random effects taking into account the clustered sampling design.

\section{Results}

RFLP-dHPLC Plasmodium species diagnosis validation

A new, high-throughput method for diagnosis using PCR amplification of the cytochrome $b$ gene, Alu I digestion, and analysis of the resultant restriction fragment polymorphisms using dHPLC has been developed. By dispensing with gel electrophoresis, this dHPLC-based method allows more rapid, highthroughput sample processing. Figure 2 shows the dHPLC profiles produced by Plasmodium DNA control samples using this technique. 


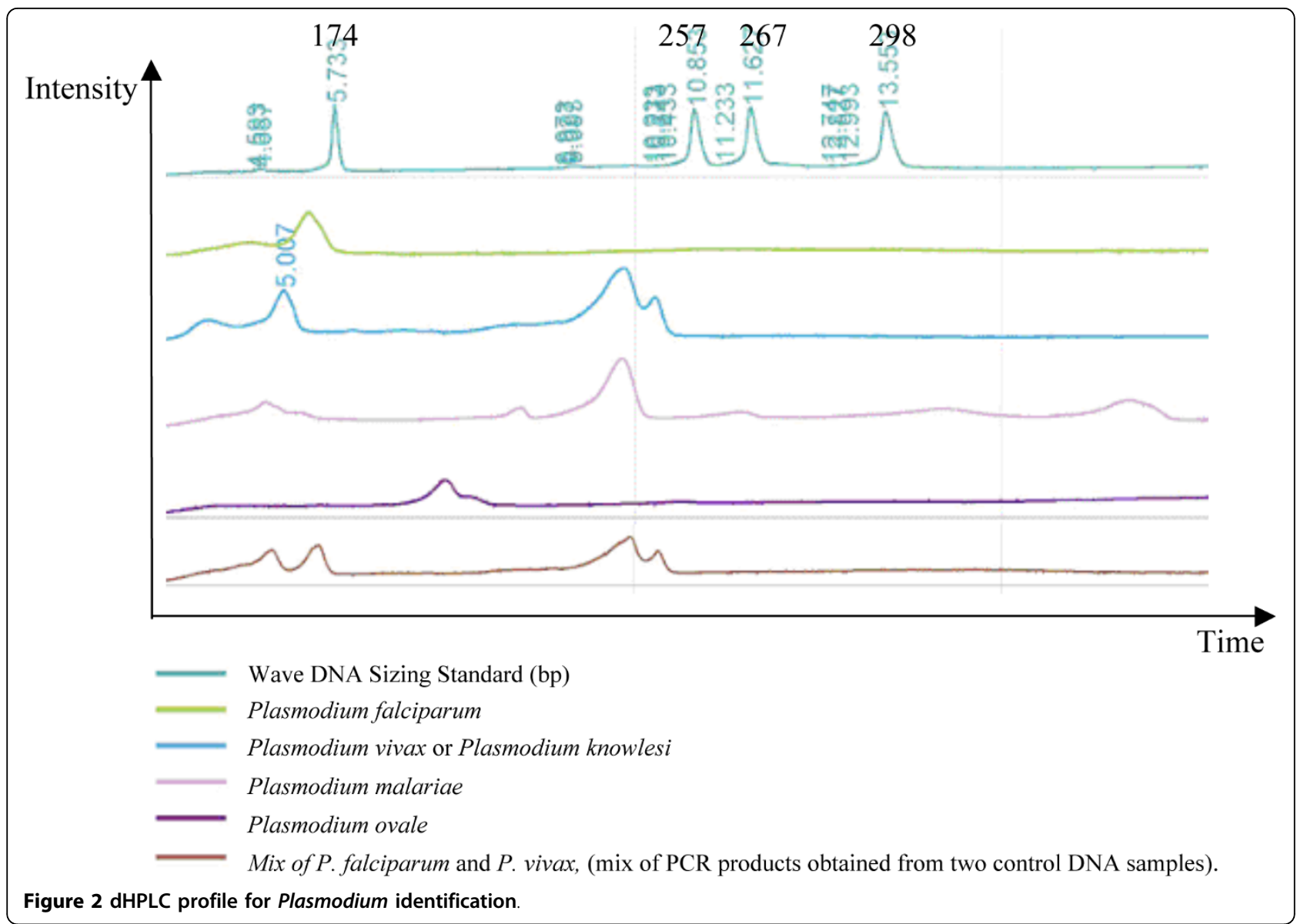

In order to ensure the accuracy of this approach, the RFLP-dHPLC method was first validated against the standard PCR methods (Table 1). All samples from one of the study sites ( $n=134$, Pahoy) were subjected to both methods. Comparison ability of the two methods to detect Plasmodium parasites, regardless of species, gave an agreement on 115 (21 negative and 94 positive). Eight samples were positive according to RFLP-dHPLC, but not according to the standard PCR and 11 were positive by the standard PCR, but not by RFLP-dHPLC. There was no evidence for the superiority of either method in detecting Plasmodium parasites (McNemar's exact test $\mathrm{p}=0.65$ ). The only difference in species identification between the two methods occurred in cases in which one test detected a mixed species infection and the other test identified only the predominant species. For example, the standard PCR approach identified eight mixed infections among 56 infections identified as $P$. falciparum mono-infections by dHPLC, while dHPLC identified four mixed infections among 48 infections identified as $P$. falciparum mono-infections by standard PCR. Twenty-three mixed infections were detected by both techniques. There was no evidence for superiority
Table 1 Comparison of results by RFLP-dHPLC and by standard PCR method in Pahoy

\begin{tabular}{|c|c|c|c|c|c|c|c|c|c|c|c|c|}
\hline \multirow{2}{*}{$\begin{array}{l}\text { RFLP- } \\
\text { dHPLC }\end{array}$} & \multicolumn{12}{|c|}{ Standard PCR } \\
\hline & neg & $F$ & v & 0 & FM & FO & FV & VM & FVM & FVO & FVMO & Tota \\
\hline neg & 21 & 4 & 4 & 0 & 0 & 0 & 0 & 0 & 0 & 0 & 0 & 29 \\
\hline $\mathrm{F}$ & 8 & 40 & 0 & 0 & 0 & 0 & 6 & 0 & 1 & 1 & 0 & 56 \\
\hline V & 1 & 0 & 6 & 0 & 0 & 0 & 2 & 1 & 0 & 0 & 0 & 10 \\
\hline M & 2 & 0 & 0 & 0 & 0 & 0 & 0 & 2 & 0 & 0 & 0 & 4 \\
\hline O & 0 & 0 & 0 & 0 & 0 & 1 & 0 & 0 & 0 & 0 & 0 & 1 \\
\hline FM & 0 & 1 & 0 & 0 & 4 & 0 & 0 & 0 & 2 & 0 & 0 & 7 \\
\hline FO & 0 & 0 & 0 & 0 & 0 & 1 & 0 & 0 & 0 & 0 & 0 & 1 \\
\hline $\mathrm{FV}$ & 0 & 3 & 2 & 0 & 0 & 0 & 10 & 0 & 0 & 0 & 2 & 17 \\
\hline VM & 0 & 0 & 0 & 0 & 0 & 0 & 0 & 0 & 1 & 0 & 0 & 1 \\
\hline VO & 0 & 0 & 0 & 2 & 0 & 0 & 0 & 0 & 0 & 0 & 0 & 2 \\
\hline FVM & 0 & 0 & 0 & 0 & 0 & 0 & 0 & 0 & 3 & 0 & 1 & 4 \\
\hline FVO & 0 & 0 & 0 & 0 & 0 & 0 & 0 & 0 & 0 & 2 & 0 & 2 \\
\hline Total & 32 & 48 & 12 & 2 & 4 & 2 & 18 & 3 & 7 & 3 & 3 & 134 \\
\hline
\end{tabular}


of either technique in detecting mixed species infections including $P$. falciparum (McNemar's exact test $\mathrm{p}=$ 0.39).

Because of the same pattern found for $P$. vivax and $P$. knowlesi in dHPLC technique, all isolates found to be infected by $P$. vivax were sequenced. No $P$. knowlesi infection was found.

Since the RFLP-dHPLC method did not appear inferior to standard PCR diagnosis, validation was done on the sequence specificity of the new method by comparing the species identification made by RFLP-dHPLC detection with the results of cytochrome $b$ SNP analysis as determined by direct DNA sequencing of cytochrome $b$ PCR products [27]. For mono-infections there were no discrepancies between the methods. In the case of mixed infections, each technique occasionally missed a minor species identified by the other (Table 2). Overall, the two techniques gave the same species identification, including mixed species, in 85/99 (86\%) of cases. In seven cases RFLP-dHPLC identified mixed infections missed by cytochrome $b$ SNP analysis; in seven cases, cytochrome $b$ SNP analysis identified mixed infections missed by RFLP-dHPLC. Since the RFLP-dHPLC method appeared no less sensitive than standard PCR and identified mixed infections as effectively as cytochrome $b$ SNP analysis, the RFLP-dHPLC method was used to assess the prevalence of sub-microscopic and mixed infections in samples from eight villages in Rattanakiri.

Table 2 Comparison of results by RFLP-dHPLC and by sequence analysis of SNP from cytochrome $b$ gene in Pahoy

\begin{tabular}{|c|c|c|c|c|c|c|c|c|c|c|c|c|}
\hline \multirow{2}{*}{$\begin{array}{l}\text { RFLP- } \\
\text { dHPLC }\end{array}$} & \multicolumn{12}{|c|}{ sequence analysis of SNP from cytochrome $b$ gene } \\
\hline & neg & $\mathbf{F}$ & V & M & FM & FO & $\mathrm{FV}$ & VM & Vo & FVM & FVO & Total \\
\hline neg & 21 & 3 & 2 & 0 & 0 & 0 & 3 & 0 & 0 & 0 & 0 & 29 \\
\hline $\mathrm{F}$ & 5 & 50 & 0 & 0 & 1 & 0 & 0 & 0 & 0 & 0 & 0 & 56 \\
\hline V & 0 & 0 & 8 & 0 & 0 & 0 & 2 & 0 & 0 & 0 & 0 & 10 \\
\hline M & 0 & 0 & 0 & 3 & 0 & 0 & 0 & 1 & 0 & 0 & 0 & 4 \\
\hline O & 0 & 0 & 0 & 0 & 0 & 1 & 0 & 0 & 0 & 0 & 0 & 1 \\
\hline FM & 0 & 1 & 0 & 1 & 4 & 0 & 0 & 0 & 0 & 1 & 0 & 7 \\
\hline FO & 1 & 0 & 0 & 0 & 0 & 0 & 0 & 0 & 0 & 0 & 0 & 1 \\
\hline $\mathrm{FV}$ & 0 & 2 & 2 & 0 & 0 & 0 & 12 & 0 & 0 & 1 & 0 & 17 \\
\hline VM & 0 & 0 & 0 & 0 & 0 & 0 & 0 & 1 & 0 & 0 & 0 & 1 \\
\hline VO & 0 & 0 & 1 & 0 & 0 & 0 & 0 & 0 & 1 & 0 & 0 & 2 \\
\hline FVM & 0 & 0 & 0 & 0 & 0 & 0 & 0 & 0 & 0 & 4 & 0 & 4 \\
\hline FVO & 0 & 0 & 0 & 0 & 0 & 0 & 0 & 0 & 0 & 0 & 2 & 2 \\
\hline Total & 27 & 56 & 13 & 4 & 5 & 1 & 17 & 2 & 1 & 6 & 2 & 134 \\
\hline
\end{tabular}

\section{Comparison of RFLP-dHPLC and microscopy results}

A comparison between the numbers of Plasmodium infections detected by microscopy and by the RFLPdHPLC method was done on 1,356 samples collected from eight villages in Rattanakiri province (Table 3). The prevalence of Plasmodium infections measured by the RFLP-dHPLC method (68.4\%, 95\%CI: $62.7 \%$ $74.1 \%)$ was more than twice that measured by microscopy (30.7\%, 95\%CI: $24.9 \%$ - 36.4\%).

Regardless of species, the two techniques agreed on 764 samples (376 positive and 388 negative according to both techniques). Nevertheless, 552 specimens negative by microscopy were positive by RFLP-dHPLC, and 40 negative by RFLP-dHPLC were positive by microscopy: 32 P. falciparum, five $P$. vivax and three mixed infections $P$. falciparum with $P$. vivax; the $P$. falciparum density is distributed as follow: 16 in class 1 of parasite densities, 14 in class 2, four in class 3 and one in class 4. The RFLP-dHPLC method identified many more infections than microscopy (McNemar's exact test $\mathrm{p}<$ $0.0001)$.

Table 4 and 5 show the prevalence of malaria infection in the individual villages as determined by both microscopy and RFLP-dHPLC. The prevalence of $P$. falciparum and $P$. vivax was approximately two-fold and three-fold higher, respectively, when measured by the RFLP-dHPLC (P. falciparum: 59.4\%, 95\%CI: 52.2\% - 66.6\%; P. vivax: $14.7 \%$, 95\%CI: $10.8 \%$ - 18.7\%) than by microscopy (P. falciparum: 28.2\%, 95\%CI: $21.6 \%$

Table 3 Comparison between microscopy and RFLPdHPLC diagnostic methods

\begin{tabular}{lccccc}
\hline RFLP-dHPLC & \multicolumn{5}{c}{ Microscopy } \\
\hline neg & neg & F & V & FV & Total \\
F & 388 & 32 & 5 & 3 & 428 \\
V & 331 & 241 & 6 & 13 & 591 \\
M & 50 & 5 & 8 & 4 & 67 \\
O & 35 & 2 & 1 & 1 & 39 \\
& 3 & 1 & 0 & 0 & 4 \\
FM & & & & & \\
FO & 59 & 24 & 3 & 2 & 88 \\
FV & 2 & 3 & 0 & 1 & 6 \\
VM & 49 & 35 & 10 & 7 & 101 \\
VO & 5 & 2 & 0 & 1 & 8 \\
& 4 & 0 & 0 & 0 & 4 \\
FVM & & & & & \\
FVO & 11 & 4 & 1 & 0 & 16 \\
FVMO & 2 & 1 & 0 & 0 & 3 \\
Total & 1 & 0 & 0 & 0 & 1 \\
\hline
\end{tabular}


Table 4 Prevalence of Plasmodium spp. by village diagnosed by microscopy (P. spp.: All Plasmodium species; Pf: Plasmodium falciparum; Pv: Plasmodium vivax; Pm: Plasmodium malariae; Po: Plasmodium ovale)

\begin{tabular}{|c|c|c|c|c|c|c|c|}
\hline \multirow[b]{3}{*}{ Village } & \multirow[b]{3}{*}{$\mathbf{N}$} & \multicolumn{6}{|c|}{ Microscopy } \\
\hline & & \multicolumn{2}{|c|}{ P. spp } & \multicolumn{2}{|r|}{ Pf } & \multicolumn{2}{|r|}{$P v$} \\
\hline & & $\%$ & IC95\% & $\%$ & IC95\% & $\%$ & IC95\% \\
\hline Yasom & 204 & $38,7 \%$ & $(32,0-45,8)$ & $36,8 \%$ & $(30,1-43,8)$ & $8,3 \%$ & $(4,9-13,0)$ \\
\hline Roy & 205 & $37,1 \%$ & $(30,4-44,1)$ & $33,2 \%$ & $(26,8-40,1)$ & $7,8 \%$ & $(4,5-12,4)$ \\
\hline Paor & 209 & $25,4 \%$ & $(19,6-31,8)$ & $23,0 \%$ & $(17,4-29,3)$ & $3,8 \%$ & $(1,7-7,4)$ \\
\hline Chet & 202 & $27,7 \%$ & $(21,7-34,4)$ & $26,2 \%$ & $(20,3-32,9)$ & $3,0 \%$ & $(1,1-6,4)$ \\
\hline Tung & 141 & $20,6 \%$ & $(14,2-28,2)$ & $14,2 \%$ & $(8,9-21,1)$ & $9,2 \%$ & $(5,0-15,3)$ \\
\hline Touch & 143 & $35,0 \%$ & $(27,2-43,4)$ & $34,3 \%$ & $(26,5-42,7)$ & $1,4 \%$ & $(0,2-5,0)$ \\
\hline Laing Av & 118 & $28,8 \%$ & $(20,8-37,9)$ & $26,3 \%$ & $(18,6-35,2)$ & $2,5 \%$ & $(0,5-7,3)$ \\
\hline Pahoy & 134 & $29,1 \%$ & $(21,6-37,6)$ & $28,4 \%$ & $(20,9-36,8)$ & $0,7 \%$ & $(0,0-4,1)$ \\
\hline
\end{tabular}

- 34.7\%; P. vivax: 4.8\%, 95\%CI: $3.1 \%$ - 6.6\%). In addition, $P$. ovale and $P$. malariae were never detected by microscopy while they were detected by RFLP-dHPLC (P. malariae: $11.2 \%$, 95\% CI: $8.2 \%-14.2 \%$; P. ovale: 1.3\%, 95\%CI: $0.04 \%-2.6 \%)$.

Prevalence of sub-microscopic $P$. falciparum infection In subjects less than five years old, microscopy and RFLP-dHPLC gave similar P. falciparum prevalences. In subjects aged five years or older, the $P$. falciparum prevalence was higher when estimated by RFLP-dHPLC than microscopy (Figure 3). The P. falciparum parasite densities estimated by microscopy decrease significantly with increasing age. No such association of age with prevalence or parasite density was found for the three other Plasmodium species.

\section{Characterization of mixed infection}

Due to the higher sensitivity of RFLP-dHPLC, the proportion of mixed infections was significantly higher with this method $(24.5 \%, 227 / 928)$ than with microscopy (7.7\%, 32/416) (Table 3). The frequency of mixed infections detected by RFLP-dHPLC did not vary significantly depending on the positivity of the microscopy $(\mathrm{p}=0.75)$ or the parasite density $(\mathrm{p}=0.91)$ estimated by microscopy.

\section{Sex and ethnic groups}

Plasmodium falciparum was more prevalent in males than in females $(\mathrm{p}<0.001)$. No such association was found for the other malaria species (Table 6). Between ethnic groups, the prevalence of $P$. falciparum and $P$. vivax, but not of $P$. malariae or $P$. ovale, differed significantly (Table 6). The prevalence of $P$. falciparum was significantly higher in the Brao than in the Tampoun and in the Tampoun than in the Jaray ethnic groups, and the prevalence of $P$. vivax was significantly higher in the Brao than in the Tampoun, without significant differences between the Jaray and the other ethnic groups.

\section{Evidence of non-random species associations}

Controlling for age and ethnic group in multivariate random effects logistic regression models, $P$. vivax infection was significantly associated with $P$. ovale infection $(\mathrm{OR}=$ 4.35, IC95 = $1.64-11.49, \mathrm{p}=0.003$ ) (Table 6). There was also an association between $P$. falciparum and $P$. malariae infections (unadjusted OR $=1.61$, IC95 $=1.12-2.32$, $\mathrm{p}=0.010$ ) that was no more significant when controlling for age (adjusted OR $=1.34$, IC95 $=0.91-1.99, \mathrm{p}=$ $0.138)$. There was no association between $P$. falciparum and $P$. vivax infection $(\mathrm{p}=0.535)$.

Table 5 Prevalence of Plasmodium spp. by village diagnosed by RFLP-dHPLC (P. spp.: All Plasmodium species; Pf: Plasmodium falciparum; Pv: Plasmodium vivax; Pm: Plasmodium malariae; Po: Plasmodium ovale)

\begin{tabular}{|c|c|c|c|c|c|c|c|c|c|c|}
\hline \multirow[b]{3}{*}{ Village } & \multicolumn{10}{|c|}{ RFLP-dHPLC } \\
\hline & \multicolumn{2}{|c|}{ P. spp. } & \multicolumn{2}{|c|}{$P f$} & \multicolumn{2}{|c|}{$P v$} & \multicolumn{2}{|c|}{$P m$} & \multicolumn{2}{|c|}{ Po } \\
\hline & $\%$ & IC95\% & $\%$ & IC95\% & $\%$ & IC95\% & $\%$ & IC95\% & $\%$ & IC95\% \\
\hline Yasom & $71,6 \%$ & $(64,8-77,6)$ & $66,7 \%$ & $(59,7-73,1)$ & $14,2 \%$ & $(9,7-19,8)$ & $10,8 \%$ & $(6,9-15,9)$ & $2,0 \%$ & $(0,5-4,9)$ \\
\hline Roy & $65,4 \%$ & $(58,4-71,9)$ & $56,1 \%$ & $(49,0-63,0)$ & $11,2 \%$ & $(7,2-16,4)$ & $9,8 \%$ & $(6,1-14,7)$ & $2,0 \%$ & $(0,5-4,9)$ \\
\hline Paor & $68,9 \%$ & $(62,1-75,1)$ & $60,3 \%$ & $(53,3-67,0)$ & $12,4 \%$ & $(8,3-17,7)$ & $15,3 \%$ & $(10,7-20,9)$ & $0,0 \%$ & $(0,0-1,7)$ \\
\hline Chet & $66,3 \%$ & $(59,4-72,8)$ & $58,9 \%$ & $(51,8-65,8)$ & $11,9 \%$ & $(7,8-17,2)$ & $5,9 \%$ & $(3,1-10,1)$ & $0,0 \%$ & $(0,0-1,8)$ \\
\hline Tung & $53,2 \%$ & $(44,6-61,6)$ & $39,0 \%$ & $(30,9-47,6)$ & $16,3 \%$ & $(10,6-23,5)$ & $12,1 \%$ & $(7,2-18,6)$ & $1,4 \%$ & $(0,2-5,0)$ \\
\hline Touch & $69,9 \%$ & $(61,7-77,3)$ & $61,5 \%$ & $(53,0-69,5)$ & $16,8 \%$ & $(11,1-23,9)$ & $13,3 \%$ & $(8,2-20,0)$ & $1,4 \%$ & $(0,2-5,0)$ \\
\hline Laing Av & $76,3 \%$ & $(67,6-83,6)$ & $67,8 \%$ & $(58,6-76,1)$ & $12,7 \%$ & $(7,3-20,1)$ & $11,9 \%$ & $(6,6-19,1)$ & $0,0 \%$ & $(0,0-3,1)$ \\
\hline Pahoy & $78,4 \%$ & $(70,4-85,0)$ & $64,9 \%$ & $(56,2-73,0)$ & $26,9 \%$ & $(19,6-35,2)$ & $11,9 \%$ & $(7,0-18,7)$ & $4,5 \%$ & $(1,7-9,5)$ \\
\hline
\end{tabular}




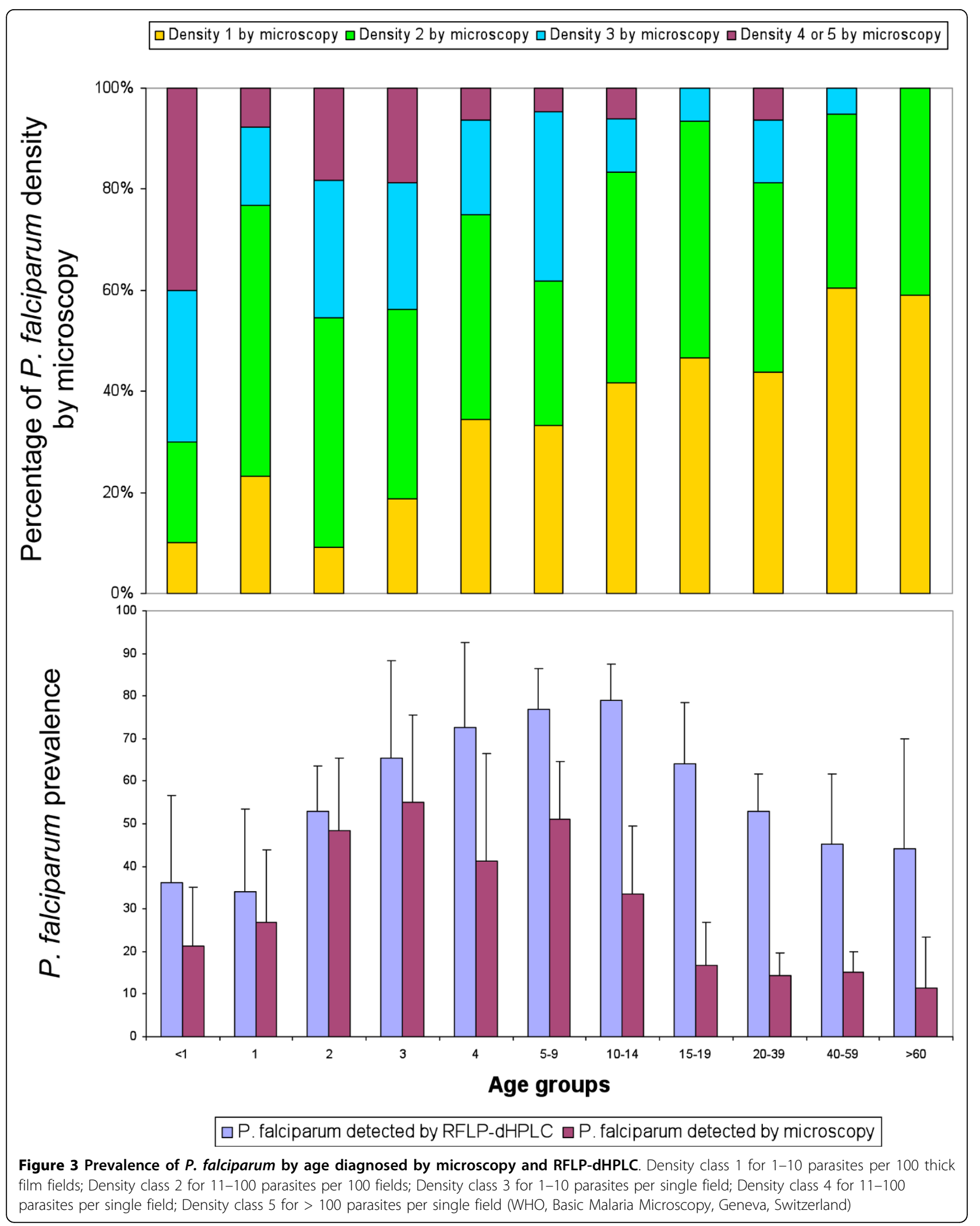


Table 6 Associations of $P$. falciparum and $P$. vivax infection with other Plasmodium infections and demographics; results of logistic regression analysis allowing for random village effects. $N=1319$ individuals from 8 villages

\begin{tabular}{|c|c|c|c|c|c|c|c|c|c|c|c|c|c|}
\hline & \multirow[b]{3}{*}{$\mathbf{N}$} & \multicolumn{5}{|c|}{ P. falciparum infections } & \multicolumn{6}{|c|}{ P. vivax infections } & \multirow[b]{3}{*}{ p-value } \\
\hline & & \multicolumn{5}{|c|}{ Prevalence } & \multicolumn{6}{|c|}{ Prevalence } & \\
\hline & & positive & rate & OR & IC95\% & & p-value & positive & rate & OR & IC95\% & & \\
\hline \multicolumn{14}{|l|}{ P. falciparum infection } \\
\hline Not detected* & 540 & & & & & & & 77 & $14,3 \%$ & 1,00 & & & \\
\hline Detected* & 779 & & & & & & & 114 & $14,6 \%$ & 0,92 & 0,66 & 1,30 & 0,647 \\
\hline \multicolumn{14}{|l|}{ P. vivax infection } \\
\hline Not detected* & 1128 & 665 & $59,0 \%$ & 1,00 & & & & & & & & & \\
\hline Detected* & 191 & 114 & $59,7 \%$ & 0,90 & 0,64 & 1,26 & 0,535 & & & & & & \\
\hline \multicolumn{14}{|l|}{ P. malariae infection } \\
\hline Not detected* & 1173 & 680 & $58,0 \%$ & 1,00 & & & & 168 & $14,3 \%$ & 1,00 & & & \\
\hline Detected* & 146 & 99 & $67,8 \%$ & 1,34 & 0,91 & 1,99 & 0,138 & 23 & $15,8 \%$ & 1,17 & 0,71 & 1,90 & 0,540 \\
\hline \multicolumn{14}{|l|}{ P. ovale infection } \\
\hline Not detected* & 1301 & 769 & $59,1 \%$ & 1,00 & & & & 183 & $14,1 \%$ & 1,00 & & & \\
\hline Detected* & 18 & 10 & $55,6 \%$ & 0,63 & 0,23 & 1,73 & 0,367 & 8 & $44,4 \%$ & 4,35 & 1,64 & 11,49 & 0,003 \\
\hline \multicolumn{14}{|l|}{ Sex } \\
\hline Female & 723 & 400 & $55,3 \%$ & 1,00 & & & & 92 & $12,7 \%$ & 1,00 & & & \\
\hline Male & 596 & 379 & $63,6 \%$ & 1,54 & 1,21 & 1,96 & $<0,001$ & 99 & $16,6 \%$ & 1,35 & 0,98 & 1,86 & 0,064 \\
\hline \multicolumn{14}{|l|}{ Age groups (years) } \\
\hline$<1$ & 50 & 14 & $28,0 \%$ & 1,00 & & & & 7 & $14,0 \%$ & 1,00 & & & \\
\hline 1 & 41 & 14 & $34,1 \%$ & 1,69 & 0,67 & 4,21 & 0,264 & 14 & $34,1 \%$ & 3,77 & 1,33 & 10,71 & 0,013 \\
\hline 2 & 66 & 35 & $53,0 \%$ & 3,35 & 1,51 & 7,46 & 0,003 & 8 & $12,1 \%$ & 0,89 & 0,30 & 2,68 & 0,838 \\
\hline 3 & 58 & 38 & $65,5 \%$ & 6,06 & 2,61 & 14,08 & $<0,001$ & 12 & $20,7 \%$ & 1,71 & 0,60 & 4,85 & 0,313 \\
\hline 4 & 51 & 37 & $72,5 \%$ & 7,99 & 3,29 & 19,43 & $<0,001$ & 7 & $13,7 \%$ & 1,02 & 0,32 & 3,20 & 0,978 \\
\hline 5-9 & 225 & 173 & $76,9 \%$ & 10,85 & 5,33 & 22,10 & $<0,001$ & 41 & $18,2 \%$ & 1,45 & 0,59 & 3,57 & 0,418 \\
\hline $10-14$ & 134 & 106 & $79,1 \%$ & 12,78 & 5,93 & 27,55 & $<0,001$ & 27 & $20,1 \%$ & 1,66 & 0,65 & 4,27 & 0,290 \\
\hline $15-19$ & 95 & 61 & $64,2 \%$ & 6,21 & 2,87 & 13,43 & $<0,001$ & 9 & $9,5 \%$ & 0,69 & 0,23 & 2,02 & 0,494 \\
\hline $20-39$ & 401 & 212 & $52,9 \%$ & 3,41 & 1,75 & 6,62 & $<0,001$ & 46 & $11,5 \%$ & 0,86 & 0,36 & 2,07 & 0,742 \\
\hline $40-60$ & 146 & 66 & $45,2 \%$ & 2,43 & 1,19 & 4,96 & 0,014 & 15 & $10,3 \%$ & 0,72 & 0,27 & 1,91 & 0,513 \\
\hline$>60$ & 52 & 23 & $44,2 \%$ & 2,48 & 1,06 & 5,79 & 0,035 & 5 & $9,6 \%$ & 0,64 & 0,19 & 2,23 & 0,488 \\
\hline \multicolumn{14}{|l|}{ Ethnic groups } \\
\hline Jaray & 269 & 133 & $49,4 \%$ & 1,00 & & & & 44 & $16,4 \%$ & 1,38 & 0,92 & 2,06 & 0,115 \\
\hline Tampoun & 801 & 482 & $60,2 \%$ & 1,86 & 1,19 & 2,90 & 0,007 & 96 & $12,0 \%$ & 1,00 & & & \\
\hline Brao & 249 & 164 & $65,9 \%$ & 2,60 & 1,52 & 4,47 & 0,001 & 51 & $20,5 \%$ & 2,03 & 1,38 & 2,99 & $<0,001$ \\
\hline
\end{tabular}

* by RFLP-dHPLC

\section{Discussion}

The detection of Plasmodium species at very low parasitaemia is difficult and requires a molecular approach. The performance of a relatively simple and semi-automated technique has been evaluated here. It is a highly sensitive PCR-based diagnostic method using amplification of a fragment of the cytochrome $b$ gene, followed by RFLP analysis using dHPLC to detect amplification and restriction products. Compared to the well established PCR typing of the $18 S$ rRNA gene for species detection, this method appeared reliable, sensitive (multi copy number of the cytochrome $b$ gene), specific and rapid (two PCR instead of five) and give the ability to amplified large number of species [27]. The dHPLC semiautomated analysis allowed the screening of a 96-well plate in $48 \mathrm{~h}$ and to diagnose 1,356 samples in less than one month.

Use of the RFLP-dHPLC method revealed a high prevalence of sub-microscopic infections. The overall prevalence detected by the RFLP-dHPLC method was twice that detected by microscopy (68.4\% versus $30.7 \%)$. Interestingly, the proportion of sub-microscopic $P$. falciparum infections, was higher in older age groups. It is possible that acquired immunity favours maintenance of sub-microscopic, asymptomatic infections. This substantial population of adults with sub-microscopic, asymptomatic $P$. falciparum infections may represent a significant challenge to malaria control programmes. Such individuals will not seek treatment and even if they were included in a mass screening and treatment 
campaign, their parasitaemia would remain invisible to light microscopy or rapid diagnostic tests. Moreover, sub-microscopic $P$. falciparum gametocyte densities may contribute importantly to mosquito infections and thus to maintaining transmission [27]. In order to have a major impact on malaria transmission, mass screening and treatment campaigns may need to use molecular screening techniques capable of identifying sub-microscopic parasitaemia.

The RFLP-dHPLC method detected many more mixed species infections than did microscopy (Table 3). Indeed, $24.5 \%$ of all malaria infections in the Rattanakiri survey included more than one species. No association was found between the level of parasitaemia and the chance that the infection would be mixed. Co-infection with $P$. vivax and $P$. ovale was more common than would be expected based on the individual prevalences of these species $(\mathrm{OR}=4.35, \mathrm{IC} 95=1.64-11.49, \mathrm{p}=0.003)$. This association could be attributed to cross-immunity that determines susceptibility to both infections [31] or to the exposure to infective bites of common vectors that transmit both species. An alternative explanation might be that both these species can produce relapses from hypnozoites. Similarly, P. falciparum and P. malariae infection were associated $(\mathrm{OR}=1.61$, IC95 $=1.12$ $2.32, \mathrm{p}=0.010)$. There was, however no association between $P$. vivax and $P$. falciparum infection.

Plasmodium falciparum and $P$. vivax infections were found at different prevalences in the different ethnic groups. Since the different groups lived in different individual villages, it is not possible to decide whether the observed differences reflect different genetic susceptibilities, as observed for some African ethnic groups [32] or simply to different local transmission intensities or other local factors.

\section{Conclusions}

Rapid diagnosis and treatment of malaria cases, vector control and protection against mosquito bites are the cornerstone of the malaria control strategy in Cambodia. Sub-microscopic infections may provide a reservoir of infection, which maintains transmission. This phenomenon has already been highlighted in Guinea Bissau [1] in Brazil [33] and Gabon [34]. The high prevalence of sub-microscopic parasitaemia within Rattanakiri Province, a site of higher malaria transmission in Cambodia, is here shown. Such infections may hamper elimination efforts, since they are asymptomatic and would not be efficiently detected by conventional diagnosis methods, i.e. microscopy or rapid diagnostic tests. Thus, the rapid and sensitive molecular diagnosis method developed here could be considered for mass screening and ACT treatment of inhabitants of low-endemicity areas of Southeast Asia to face the urgent need to eradicate malaria in Cambodia due to emerging artemisinin resistance in the country.

\section{Ethical approval}

Ethical approval for this study was granted by the National Ethics Committee of the Kingdom of Cambodia.

\section{Acknowledgements}

The authors thank the staff of the National Center for Parasitology, Entomology and Malaria Control as well as the staff of the European Commission National Malaria Control Programme for sample collection and for the examination of the blood slides.

Thanks go to Jonathan Cox who provided GPS position of the study villages. The work was funded by a grant from Institut Pasteur à Paris (Modipop project). The opinions expressed are the personal ones of the authors and do not purport to represent those of the U.S. Navy.

\section{Author details}

${ }^{1}$ Unité d'Epidémiologie Moléculaire, Institut Pasteur du Cambodge, Phnom Penh, Cambodia. ${ }^{2}$ Naval Medical Research Center Unit 2, Jakarta 10560 Indonesia. ${ }^{3}$ London School of Hygiene \& Tropical Medicine (LSHTM), London, UK. ${ }^{4}$ Centre de recherche médicale et sanitaire (CERMES), Niamey, Niger. ${ }^{5}$ Laboratoire de Génétique de la réponse aux infections chez l'homme, Institut Pasteur, Paris, France. ${ }^{6}$ European Commission National Malaria Control Program, Phnom Penh, Cambodia. ${ }^{7}$ Rodolphe Mérieux Laboratory of Cambodia, University of Health Science, Phnom Penh, Cambodia. ${ }^{8}$ National Center for Parasitology, Entomology and Malaria Control, Phnom Penh, Cambodia. ${ }^{9}$ Fondation Mérieux, Phnom Penh, Cambodia. ${ }^{10}$ Equipe « Moustiques et Maladies Emergentes»- UMR 6236 - URMITE, Unité de Recherche en Biologie et Epidémiologie Parasitaires - Institut de Recherche Biomédicale des Armées, Marseille, France.

\section{Authors' contributions}

NS, LD and FA conceived and designed the genus-specific nested PCR and SNP identification based on the cytochrome $b$ gene, SH and SD lead the field work, NS, SI, MC, FX, SC managed the experimental procedure and performed the laboratory work, NS, CR, WR, LO, FA participated in the statistical analyses, NS, IJ participated in SIG work. NS, WR, LO, IJ, SI, LD, SC, $\mathrm{SH}, \mathrm{DS}, \mathrm{FB}, \mathrm{FA}, \mathrm{CR}$ drafted and critically revised the manuscript. All authors read and approved manuscript.

\section{Competing interests}

The authors declare that they have no competing interests.

Received: 19 September 2009 Accepted: 22 April 2010

Published: 22 April 2010

\section{References}

1. Snounou G, Pinheiro L, Goncalves A, Fonseca L, Dias F, Brown KN, do Rosario VE: The importance of sensitive detection of malaria parasites in the human and insect hosts in epidemiological studies, as shown by the analysis of field samples from Guinea Bissau. Trans $R$ Soc Trop Med Hyg 1993, 87:649-653.

2. Singh $B$, Cox-Singh J, Miller AO, Abdullah MS, Snounou G, Rahman HA: Detection of malaria in Malaysia by nested polymerase chain reaction amplification of dried blood spots on filter papers. Trans $R$ Soc Trop Med Hyg 1996, 90:519-521.

3. Toma H, Kobayashi J, Vannachone B, Arakawa T, Sato Y, Nambanya S, Manivong $K$, Inthakone S: A field study on malaria prevalence in southeastern Laos by polymerase chain reaction assay. Am J Trop Med Hyg 2001, 64:257-261.

4. Alves FP, Durlacher RR, Menezes MJ, Krieger H, Silva LH, Camargo EP: High prevalence of asymptomatic Plasmodium vivax and Plasmodium falciparum infections in native Amazonian populations. Am J Trop Med Hyg 2002, 66:641-648.

5. Neri S, Pulvirenti D, Patamia I, Zoccolo A, Castellino P: Acute renal failure in Plasmodium malariae infection. Neth J Med 2008, 66:166-168. 
6. White NJ: Plasmodium knowlesi: the fifth human malaria parasite. Clin Infect Dis 2008, 46:172-173.

7. Cox-Singh J, Singh B: Knowlesi malaria: newly emergent and of public health importance? Trends Parasitol 2008, 24:406-410.

8. Voza T, Vigario AM, Belnoue E, Gruner AC, Deschemin JC, Kayibanda M, Delmas F, Janse CJ, Franke-Fayard B, Waters AP, Landau I, Snounou G, Renia L: Species-specific inhibition of cerebral malaria in mice coinfected with Plasmodium spp. Infect Immun 2005, 73:4777-4786.

9. Black J, Hommel M, Snounou G, Pinder M: Mixed infections with Plasmodium falciparum and P. malariae and fever in malaria. Lancet 1994, 343:1095.

10. Gunewardena DM, Carter R, Mendis KN: Patterns of acquired anti-malarial immunity in Sri Lanka. Mem Inst Oswaldo Cruz 1994, 89(Suppl 2):63-65.

11. Luxemburger C, Ricci F, Nosten F, Raimond D, Bathet S, White NJ: The epidemiology of severe malaria in an area of low transmission in Thailand. Trans R Soc Trop Med Hyg 1997, 91:256-262.

12. Molineaux L, Storey J, Cohen JE, Thomas A: A longitudinal study of human malaria in the West African Savanna in the absence of control measures: relationships between different Plasmodium species, in particular P. falciparum and P. malariae. Am J Trop Med Hyg 1980, 29:725-737.

13. Maitland K, Williams TN, Newbold Cl: Plasmodium vivax and P. falciparum: Biological interactions and the possibility of cross-species immunity. Parasitol Today 1997, 13:227-231.

14. Mayxay M, Pukrittayakamee S, Newton PN, White NJ: Mixed-species malaria infections in humans. Trends Parasitol 2004, 20:233-240.

15. Price RN, Nosten F, Luxemburger C, van Vugt M, Phaipun L, Chongsuphajaisiddhi T, White $\mathrm{NJ}$ : Artesunate/mefloquine treatment of multi-drug resistant falciparum malaria. Trans R Soc Trop Med Hyg 1997, 91:574-577.

16. Smith T, Genton B, Baea K, Gibson N, Narara A, Alpers MP: Prospective risk of morbidity in relation to malaria infection in an area of high endemicity of multiple species of Plasmodium. Am J Trop Med Hyg 2001, 64:262-267.

17. Alifrangis M, Lemnge MM, Moon R, Theisen M, Bygbjerg I, Ridley RG, Jakobsen PH: IgG reactivities against recombinant Rhoptry-Associated Protein-1 (rRAP-1) are associated with mixed Plasmodium infections and protection against disease in Tanzanian children. Parasitology 1999, 119:337-342.

18. Sedegah M, Weiss WW, Hoffman SL: Cross-protection between attenuated Plasmodium berghei and P. yoelii sporozoites. Parasite Immunol 2007, 29:559-565.

19. Snounou G, Viriyakosol S, Jarra W, Thaithong S, Brown KN: Identification of the four human malaria parasite species in field samples by the polymerase chain reaction and detection of a high prevalence of mixed infections. Mol Biochem Parasitol 1993, 58:283-292.

20. Zhou M, Liu Q, Wongsrichanalai C, Suwonkerd W, Panart K, Prajakwong S, Pensiri A, Kimura M, Matsuoka H, Ferreira MU, Isomura S, Kawamoto F: High prevalence of Plasmodium malariae and Plasmodium ovale in malaria patients along the Thai-Myanmar border, as revealed by acridine orange staining and PCR-based diagnoses. Trop Med Int Health 1998, 3:304-312.

21. Kawamoto F, Liu Q, Ferreira MU, Tantular IS: How prevalent are Plasmodium ovale and P. malariae in East Asia? Parasitol Today 1999, 15:422-426.

22. Snounou G, White NJ: The co-existence of Plasmodium: sidelights from falciparum and vivax malaria in Thailand. Trends Parasitol 2004, 20:333-339.

23. Denis MB, Meek SR: Malaria in Cambodia. Southeast Asian J Trop Med Public Health 1992, 23:23-28.

24. Socheat D, Denis MB, Fandeur T, Zhang Z, Yang $H$, Xu J, Zhou $X$, Phompida S, Phetsouvanh R, Lwin S, Lin K, Win T, Than SW, Htut Y, Prajakwong S, Rojanawatsirivet C, Tipmontree R, Vijaykadga S, Konchom S, Cong le D, Thien NT, Thuan le K, Ringwald P, Schapira A, Christophel E, Palmer K, Arbani PR, Prasittisuk C, Rastogi R, Monti F, Urbani C, Tsuyuoka R, Hoyer S, Otega L, Thimasarn K, Songcharoen S, Meert JP, Gay F, Crissman L, Cho Min Naing, Chansuda W, Darasri D, Indaratna K, Singhasivanon P. Chuprapawan S, Looareesuwan S, Supavej S, Kidson C, Baimai V, Yimsamran S, Buchachart K: Mekong malaria. II. Update of malaria, multidrug resistance and economic development in the Mekong region of Southeast Asia. Southeast Asian J Trop Med Public Health 2003, 34:1-102.
25. Annual Progress Reports 2000 - 2007. National Center for Parasitology, Entomology and Malaria Control, Ministry of Health of Cambodia, Phnom Penh, Cambodia .

26. Sochantha T, Hewitt S, Nguon C, Okell L, Alexander N, Yeung S, Vannara H, Rowland M, Socheat D: Insecticide-treated bednets for the prevention of Plasmodium falciparum malaria in Cambodia: a cluster-randomized trial. Trop Med Int Health 2006, 11:1166-1177.

27. Steenkeste N, Incardona S, Chy S, Duval L, Ekala MT, Lim P, Hewitt S, Sochantha T, Socheat D, Rogier C, Mercereau-Puijalon O, Fandeur T, Ariey F: Towards high-throughput molecular detection of Plasmodium: new approaches and molecular markers. Malar J 2009, 8:86.

28. Snounou G, Viriyakosol S, Zhu XP, Jarra W, Pinheiro L, do Rosario VE, Thaithong S, Brown KN: High sensitivity of detection of human malaria parasites by the use of nested polymerase chain reaction. Mol Biochem Parasitol 1993, 61:315-320.

29. Singh B, Bobogare A, Cox-Singh J, Snounou G, Abdullah MS, Rahman HA: A genus- and species-specific nested polymerase chain reaction malaria detection assay for epidemiologic studies. Am J Trop Med Hyg 1999, 60:687-692.

30. Duval L, Robert V, Csorba G, Hassanin A, Randrianarivelojosia M, Walston J Nhim T, Goodman SM, Ariey F: Multiple host-switching of Haemosporidia parasites in bats. Malar J 2007, 6:157.

31. Collins WE, Jeffery GM: A retrospective examination of sporozoiteinduced and trophozoite-induced infections with Plasmodium ovale: development of parasitologic and clinical immunity during primary infection. Am J Trop Med Hyg 2002, 66:492-502.

32. Modiano D, Petrarca V, Sirima BS, Nebie I, Diallo D, Esposito F, Coluzzi M: Different response to Plasmodium falciparum malaria in west African sympatric ethnic groups. Proc Natl Acad Sci USA 1996, 93:13206-13211.

33. Alves FP, Gil LH, Marrelli MT, Ribolla PE, Camargo EP, Da Silva LH: Asymptomatic carriers of Plasmodium spp. as infection source for malaria vector mosquitoes in the Brazilian Amazon. J Med Entomol 2005, 42:777-779.

34. Dal-Bianco MP, Koster KB, Kombila UD, Kun JF, Grobusch MP, Ngoma GM, Matsiegui PB, Supan C, Salazar CL, Missinou MA, Issifou S, Lell B, Kremsner P. High prevalence of asymptomatic Plasmodium falciparum infection in Gabonese adults. Am J Trop Med Hyg 2007, 77:939-942.

doi:10.1186/1475-2875-9-108

Cite this article as: Steenkeste et al: Sub-microscopic malaria cases and mixed malaria infection in a remote area of high malaria endemicity in Rattanakiri province, Cambodia: implication for malaria elimination. Malaria Journal 2010 9:108.

\section{Submit your next manuscript to BioMed Central and take full advantage of:}

- Convenient online submission

- Thorough peer review

- No space constraints or color figure charges

- Immediate publication on acceptance

- Inclusion in PubMed, CAS, Scopus and Google Scholar

- Research which is freely available for redistribution

Submit your manuscript at www.biomedcentral com/submit
Biomed Central 